\title{
INVESTIGACIÓN/RESEARCH
}

\section{¿ES LA JURISPRUDENCIA FUENTE DEL DERECHO?}

\section{Luis Bueno Ochoa.}

«Rara vez puede decirse, si es que puede decirse alguna, que un caso es tan completamente idéntico a otro que no hay un posible fundamento para la distinción». (Jerome Frank, Courts on Trial)

\section{Obertura y tomas de posición favorable y discrepante}

La respuesta a la pregunta que hace las veces de título bien pudiera verse introducida a través de ese otro interrogante que daba título a un famoso opúsculo kantiano: «¿Qué es la llustración?» (1783). En un célebre párrafo incluido en esa obrita del genio de Königsberg se aludía a la necesidad de salir de una autoculpable minoría de edad; a la autodeterminación, vista como imprescindible autonomía y, en síntesis, la respuesta a la pregunta venía dada en forma de exclamación: Sapere aude! El fenómeno ilustrado pasaba, pues, por una exigencia que no era otra sino atreverse a pensar.

El atrevimiento pudiera no ser algo desechable a la hora de plantearnos dar respuesta a nuestra pregunta-título. Ese atreverse a pensar, en el caso de la resolución de la conflictividad interhumana, podría transmutarse en una exigencia de gran calado como es la obligación de motivar. Y es que la motivación de las sentencias, obligación comprendida en el artículo 120 de la Constitución (CE), merecerá, con el tiempo, la cobertura del reproche de la responsabilidad disciplinaria estatuida en la Ley Orgánica del Poder Judicial (LOPJ) al reputarse falta muy grave la absoluta y manifiesta falta de motivación de las resoluciones judiciales que la precisen, siempre que dicha ausencia de motivación fuese apreciada en resolución judicial firme.

La exigencia de motivación constituye, como veremos, un auténtico valladar contra la arbitrariedad; recuérdese, en este sentido, el tenor literal del artículo 9.3 CE, en sede de garantías, al sancionar la interdicción de la arbitrariedad de los poderes Recibido: 01/03/1996---Aceptado: 16/04/1996---Publicado: 12/11/1996 
públicos. Lo arbitrario es aquello que no se acomoda a la legalidad de tal forma que, frente a una actividad reglada, la arbitrariedad supone una infracción de la norma, y ante una actividad no reglada o discrecional conlleva una desviación de poder. En conexión con el principio de igualdad, el Tribunal Constitucional se ha referido a este principio, por ejemplo, en la STC $71 / 1993$, de 1 de marzo, en los términos que siguen: "A través de numerosas resoluciones este Tribunal ha establecido una constante y uniforme doctrina según la cual el derecho a la igualdad en la aplicación de la ley, protegido por el artículo 14 CE y conectado con el principio de interdicción de la arbitrariedad de los poderes públicos que consagra el artículo 9.3 CE, significa, en relación con el ejercicio de la potestad jurisdiccional, que un mismo Juez o Tribunal no puede modificar el sentido de sus decisiones adoptadas con anterioridad en casos sustancialmente idénticos, a no ser que se aparte conscientemente de él, ofreciendo una fundamentación suficiente y razonable que motive el cambio de criterio o, en ausencia de tal motivación expresa, resulte patente que la diferencia de trato tiene su fundamento en un efectivo cambio de criterio por desprenderse así de la propia resolución judicial o por existir otros elementos de juicio externo que así lo indiquen".

La motivación de las sentencias y, en general, de las resoluciones judiciales puede constituir un marco adecuado para responder a la cuestión que nos ocupa. Ni que decir tiene, a mayor abundamiento, que la exigencia de motivación está íntimamente conectada con el principio de tutela judicial efectiva y, desde luego, con el instituto de la indefensión (art. 24.1 CE); toda vez que la ausencia de motivación haría ilusorio, en verdad, el acceso al sistema de recursos.

Si todo cuanto antecede provee, como queda dicho, de un marco adecuado para el abordaje de lo que debe concentrar nuestra atención, planteémonos dar una respuesta inicial, una suerte de «pre-respuesta», al interrogante recurriendo, sin más, al primero de los artículos del Código Civil (Cc); a cuyo Título Preliminar, constatémoslo, se le reconoce (aun cuando provenga de fecha anterior a 1978), según la más autorizada doctrina, carácter cuasiconstitucional.

Pues bien, bastará, por el momento, hacernos eco de los incisos 1 y 6 del mencionado precepto para anticipar una respuesta que podría consistir en decir «no, pero sí»; o, dicho de otro modo, "sí, pero no». La jurisprudencia, por un lado, no está incluida en la relación, a modo de numerus clausus, de fuentes del Derecho que integran la ley, la costumbre y los principios generales del Derecho; y, por otro, se apunta el carácter complementario -e integrador- que expresamente se reconoce a «... la doctrina que, de modo reiterado, establezca el Tribunal Supremo al interpretar y aplicar la ley, la costumbre y los principios generales del derecho". En resumidas cuentas, vuelve a manifestarse el eco kantiano, en este caso el inquietante desdoblamiento entre la teoría y la práctica, pudiendo decir, en consecuencia, que la jurisprudencia no es fuente del Derecho en teoría pero sí en la práctica (o, viceversa, según se mire, atendiendo a la vieja máxima, según la cual, «aquello que es verdad en teoría no tiene por qué serlo en la práctica»); otra forma de expresar, valdría decir, que si bien la jurisprudencia no es fuente formal del Derecho sí es, en cambio, fuente material del Derecho. 
No parece fácil, como puede colegirse de lo expuesto hasta ahora, despejar el terreno a la hora de pronunciarse, a favor o en contra, sobre el reconocimiento de fuerza vinculante de la jurisprudencia proveniente del Tribunal Supremo. No será redundante dejar constancia de que, precisamente, ese reconocimiento de fuerza vinculante es el que supondría aceptar su inclusión en la categoría de fuente del Derecho y, por ende, concluir con una respuesta afirmativa al interrogante del título.

Antes de acometer, con brevedad, el examen de las razones que asisten a las dos posiciones -favorable o discrepante- enfrentadas, no deja de resultar llamativo que el discutido rol que puede llegar a asignarse a la producción proveniente del Tribunal Supremo no deje entrever, con similar o idéntica extrañeza, la trascendencia que se desprende de lo prescrito en el artículo 5.1 LOPJ; repárese que según el precitado artículo cuando la jurisprudencia provenga del Tribunal Constitucional, en tal caso la doctrina emanada de dicho Tribunal sí tendrá carácter vinculante. Parecería, pues, que, hasta el momento, sería sólo «imperante» la doctrina del Tribunal Constitucional y no, en cambio, la del Tribunal Supremo; y todo ello sin dejar de subrayar el antedicho carácter complementario -e integrador- reconocido a la doctrina que, de modo reiterado, establezca el Tribunal Supremo y sin omitir, tampoco, la vislumbrada importancia de mecanismos -o remedios procesales- como los recursos por razón de interés casacional, en interés de ley o de unificación de doctrina.

Aun reconociendo las dificultades de orden práctico que encierra la posibilidad de dotar de fuerza vinculante a la jurisprudencia del Tribunal Supremo, que es, en ocasiones, no sólo cambiante sino también contradictoria; el alcance reconocido a la prudentia iuris ( al conocimiento de las cosas divinas y humanas, a la ciencia de lo justo y de lo injusto», según la archiconocida fórmula de Ulpiano, en la que se acaban integrando lo justo -iustitia- y lo útil -utilitas-) sí es, en efecto, un factor que permite marcar las diferencias entre el sistema anglosajón, predominantemente consuetudinario y de creación judicial (Common-law), y el sistema continental, el denominado Statute-law, que atiende, en lo fundamental, a los ideales (léanse, aspiraciones) de certeza, seguridad y notoriedad.

Pues bien, sin desdeñar la relevancia derivada de la distinción precedente corresponde ahora extractar qué argumentos presiden la postura favorable y la contraria al señalado carácter vinculante de la jurisprudencia del Tribunal Supremo.

\section{Argumentario a favor y en contra}

Aunque sea a costa de resultar excesivamente sintético y, por tanto, a riesgo de incurrir en un planteamiento en exceso superficial, sí pueden advertirse cuáles son los argumentos de mayor peso que, enfrentadamente, se suelen invocar. 


\subsection{A favor de la jurisprudencia como fuente del Derecho}

La postura favorable se apoya, sobre todo, en la seguridad jurídica (art. 9.3 CE); entendiendo que la claridad y calidad de las leyes exige, en aras de la estabilidad necesaria para un funcionamiento adecuado -y general- de la (administración de) justicia, certeza y previsibilidad de las resoluciones judiciales. La nota de la seguridad jurídica viene a ser, pues, el marchamo necesario para una pretendida uniformidad de decisiones; que inspiraría lo que en el ámbito de la acción política viene a ser, mutatis mutandis, el tan ansiado consenso. Remedios procesales, como los antes mencionados, motorizados a través del sistema de recursos apuntan indefectiblemente en esa dirección; es decir, aquella que permite a la seguridad jurídica erigirse, a su vez, en corolario del principio de igualdad jurídica del artículo $14 \mathrm{CE}$. A este respecto es dable significar que son dos las perspectivas que abarca el contenido constitucional del invocado artículo $14 \mathrm{CE}$; a saber: la igualdad ante la ley, en un caso; y la igualdad en la aplicación de la ley, en otro.

Mientras la primera versión interpretativa tiene que ver con la exigencia de que ante supuestos de hechos iguales las consecuencias sean la mismas, proscribiendo toda desigualdad arbitraria y no justificada por los poderes públicos; la segunda, en cambio, se produce como consecuencia de la actuación judicial exigiéndose, en tal caso, que las resoluciones judiciales sean las mismas cuando se analizan los mismos presupuestos de hecho, aunque sean órganos jurisdiccionales distintos los que conozcan del asunto, pues dicha diversidad de conocimiento puede dar origen a una diferenciación en el pronunciamiento final y en la aplicación jurisdiccional que suponga una contravención cuando un mismo precepto se aplique en casos iguales con notoria desigualdad.

Convendrá añadir, como tantas veces ha hecho notar el Tribunal Constitucional, que la igualdad lo es ante la ley y ante la aplicación de la ley y constituye un valor preeminente en el ordenamiento jurídico (SSTC 103 y 104/83, 8/86, entre otras). La jurisprudencia constitucional se ha ocupado de relacionar qué caracteres articulan, en su doble acepción, el mencionado principio de igualdad; a saber: "a) vincula a todos los poderes públicos; b) no prohíbe que el legislador contemple diferenciar situaciones distintas y darles un tratamiento diverso; c) ha de darse una relación razonable de proporcionalidad entre los medios empleados y la finalidad perseguida; d) la adecuación a la interpretación a las exigencias del caso, o la adaptación del sentido de la norma a las exigencias de la realidad social del tiempo en que ha de ser aplicable, no entraña desigualdad arbitraria, proscrita en el artículo 14 de la Constitución; e) la igualdad ante la ley no puede transformarse en una exigencia de trato igual a todos fuera de la legalidad; f) un mismo órgano no puede modificar arbitrariamente el sentido de sus decisiones en casos sustancialmente iguales, y cuando considere que debe apartarse de sus precedentes tiene que ofrecer una 
fundamentación suficiente y razonable (SSTC 63/84, 64 /84, 49/85 y 52/86); g) el principio de igualdad en aplicación de la ley ha de cohonestarse con el principio de independencia de los órganos encargados de la aplicación de la ley; h) la apreciación de la posible vulneración exige que se aporte un término de comparación respecto al que la desigualdad tuviese lugar».

En otro orden de cosas, corresponde ahora poner en relación esa doble versión de la igualdad con el principio de seguridad jurídica; esta es, como enseña el Tribunal Constitucional, "suma de certeza y legalidad, jerarquía y publicidad normativa, irretroactividad de lo no favorable, interdicción de la arbitrariedad, pero que, si se agotara en la adición de estos principios, no hubiera precisado de ser formulada expresamente. La seguridad jurídica es la suma de estos principios, equilibrada de tal suerte que permita promover, en el orden jurídico, la justicia y la igualdad, en

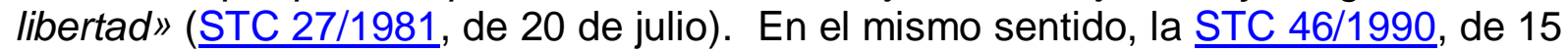
de marzo se refiere a este principio en estos otros términos: "la exigencia del artículo 9.3 relativa al principio de seguridad jurídica implica que el legislador debe perseguir la claridad y no la confusión normativa, debe procurar que acerca de la materia sobre la que legisle sepan los operadores jurídicos y los ciudadanos a qué atenerse, y debe huir de provocar situaciones objetivamente confusas [...]. Hay que promover y buscar la certeza respecto a qué es Derecho y no... provocar juegos y relaciones entre normas como consecuencia de las cuales se introducen perplejidades difícilmente salvables respecto a la previsibilidad de cuál sea el Derecho aplicable, cuáles las consecuencias derivadas de las normas vigentes, incluso cuáles sean estas".

\subsection{En contra de la jurisprudencia como fuente del Derecho}

La postura discrepante, en cambio, se atiene, entre otras consideraciones como la quiebra de la división de poderes, por ejemplo, al principio de independencia y responsabilidad judicial (art. 117.1 CE).

El citado precepto señala que los Jueces y Magistrados están «sometidos únicamente al imperio de la Ley»; añadiéndose en el artículo siguiente que "Es obligado cumplir las sentencias y demás resoluciones judiciales firmes de los Jueces y Tribunales", sin que medie distinción de ninguna clase a este respecto (es decir, sin que puedan ser consideradas más o menos vinculantes) por el hecho de que dichas resoluciones hayan sido dictadas por el Tribunal Supremo. La creación judicial del Derecho encuentra además otros obstáculos que incluso harían seriamente discutible su encaje en el texto constitucional: repárese, por de pronto, en el alcance reconocido a la reserva prevenida en el artículo 66 CE.

El principio cardinal de sometimiento a la ley está también íntimamente ligado a la proclamación de la independencia de Jueces y Magistrados que hace el expresado artículo 117 CE y que se encuentra corroborado por los artículos 12 a 14 LOPJ. Estos preceptos garantizan la independencia de Jueces y Magistrados en el ejercicio de la potestad jurisdiccional respecto a todos los órganos judiciales y de gobierno del Poder Judicial, lo que se traduce en la imposibilidad por parte de Jueces y 
Tribunales de corregir la aplicación o interpretación del ordenamiento jurídico hecha por sus inferiores en el orden jerárquico judicial, a no ser que administren justicia en virtud de los recursos que las leyes establezcan. Igualmente, tampoco pueden los Jueces y Tribunales, órganos de gobierno de los mismos o el Consejo General del Poder Judicial, dictar instrucciones, de carácter general o particular, dirigidas a sus inferiores sobre la aplicación o interpretación del ordenamiento jurídico que lleven a cabo en el ejercicio de su función jurisdiccional. Asimismo, el propio artículo 14 LOPJ comprende la facultad a los Jueces y Magistrados que se consideren inquietados o perturbados en su independencia para ponerlo en conocimiento del Consejo General del Poder Judicial, sin perjuicio, claro está, de las acciones que puede promover el Ministerio Fiscal en defensa de la independencia judicial ex artículo 124.1 CE.

Visto todo cuanto precede tenemos, en un caso, seguridad jurídica $y$, como corolario, la igualdad que proscribe la interdicción de la arbitrariedad; y, en el otro, la independencia judicial, cuyo reverso no puede ser otro sino la exigencia de responsabilidad.

Seguridad jurídica versus independencia-responsabilidad judicial se configuran, pues, como dos polos que definen, sucinta y, posiblemente de manera superficial, mas indicativa, una controversia a la que ahora se añadirán algunos otros criterios susceptibles de ser objeto de consideración.

\section{Terminación con algunos otros criterios a considerar}

Se añadirán dos series de criterios más en el bien entendido que será el carácter indicativo, nuevamente, el que informará este apartado ya presto a la conclusión.

El primero de los criterios que va a ser considerado quedará circunscrito al plano de constitucionalidad.

El segundo criterio tendrá como referente la -inmensa- mayoría de los miembros que integran la carrera judicial, es decir, aquellos que no forman parte de la elite judicial que integra el Tribunal Supremo.

Desde la perspectiva constitucional podría mantenerse que el conflicto de poderes a que sería reenviada esta cuestión en último término, o más exactamente, la colisión entre derechos que encierra la polémica, esto es, la seguridad jurídica, de un lado, y de otro, el par independencia-responsabilidad, debe quedar resuelta a favor de este último. El binomio independencia-responsabilidad está relacionado, evidentemente, con el valor de la libertad; que es concebido, a su vez, no sólo como un valor superior del ordenamiento jurídico (art. 1.1 CE) sino también como un derecho 
fundamental (arts. 16 y $17 \mathrm{CE}$ ). Por el contrario, la seguridad jurídica, como es sabido, no es susceptible de ser invocada en amparo ante el Tribunal Constitucional toda vez que no le es reconocida a la misma la categoría de derecho fundamental. Por lo expuesto, se estaría, pues, en el caso de comprobar que ya a partir de la propia estructura del texto fundamental quedaría resuelta en sentido negativo la controvertida propuesta acerca del carácter vinculante de la jurisprudencia del Tribunal Supremo.

Como segunda consideración podría ser también tenido en cuenta, según lo anticipado, el resto -esto es, la mayoría- de los integrantes del Poder Judicial. Si el indiscutible carácter complementario de la jurisprudencia pasara a convertirse en vinculante, la transmutación sería tal que la auctoritas -o sabiduría reconocidaoriginaria que es propia de la función de «juzgar»-actos de judicación- se vería transformada en potestas -o poder de mando- más afín a la función, también jurisdiccional ex artículo 117.3 CE, de «hacer ejecutar lo juzgado»-actos de jurisdicción-, subvirtiéndose así el fundamento que es consustancial a la tarea judicial; a saber: la motivación que acoge la convicción alcanzada, de manera privilegiada, a través de la inmediación. La labor del Tribunal Supremo consiste, ciertamente, no tanto en «juzgar» sino en «revisar lo juzgado». Los sucesivos filtros previos pueden convertir los asuntos sometidos a su jurisdicción, en no pocas ocasiones, en «casos de laboratorio» en los que se pierda -o se vea muy diluido- el problema humano (del tipo que sea: económico, penal, familiar, etc...) del que está imbuido cualquier asunto en sede jurisdiccional. La rigidez a que podría conducir esa clase de frío cientificismo correría el peligro de traducirse en rutina (ya se sabe, tratar de idéntica manera supuestos que no fueran iguales; aunque cabría preguntarse -volverse a preguntar- retomando la cita de la entradilla, como carencia genérica de la jurisprudencia, si puede hablarse, con rigor, de casos iguales). La arbitrariedad (expresamente vedada en el art. 9.3 in fine CE) y el inmovilismo resultante acecharían, o, cuanto menos, estarían en disposición de hacerlo ante la disminución de elementos de (auto)control (léase, motivación); y es que, por paradójico que resulte, el remedio pergeñado podría terminar erigiéndose en una vía que nos alejara de la tarea de razonar (motivar-persuadir-convencer) en torno a hechos y argumentos jurídicos que es -y debe ser- siempre el cometido que es inherente al (Estado de) Derecho.

La claridad y la certeza de la -letra de la- ley precisan, qué duda cabe, de la orientación que resulta de una jurisprudencia integradora a través de la dimensión práctica o real. De una jurisprudencia que «enseñe» con razonamientos; pero que no se imponga, sin más, por el «poder de mando» que le confiera, eventualmente, el Estado a través de mecanismos, herramientas -o remedios- articulados a través del Derecho-Legislación.

La respuesta a la pregunta del título podría verse respondida, antes de poner el punto y final, retomando el doble escepticismo característico del autor citado en la entradilla. La «duda metódica» de Jerome Frank se desplegó con su particular versión del «realismo jurídico»-legal realism - denominado «escepticismo jurídico constructivo» -constructive legal scepticism- acogedor del rule-scepticism (escepticismo ante la eficacia normativa de las reglas generales) y del factscepticism (escepticismo ante la dificultad de apreciar debidamente los hechos -«los 
hechos son conjeturas»- objeto de prueba). Sus críticas vertidas contra el academicismo del «jurista de sillón» o el «mito del tribunal superior» (que revisa lo juzgado pero al que está vedado «revisar lo juzgado», salvo excepciones, en cuanto al establecimiento de los hechos jurídicamente relevantes como momento estelar de la interpretación-aplicación judicial del Derecho) pueden ofrecer pistas fiables a la hora de tomar posición. La indeterminación lógica de la ratio decidenci, al decir de Frank, podría verse envuelta, decididamente, en el llamado «argumento del tesoro oculto» que no podrá terminar de superar esa confusión anfibológica, más que equívoca, dialéctica, recurrente tanto a propósito de la quaestio iuris como de la quaestio facti que dinamizan el mundo del Derecho. La respuesta a la pregunta del título, llegados a este punto, está servida. La incertidumbre escéptica tiene más que ver con la independencia-responsabilidad y se impone, pues, a ese afán de ilusoria e imposible seguridad que, por cierto, no tiene por qué estar reñida con una eventual impredecibilidad de las tomas de decisión.

El trasfondo escéptico acaba impregnándolo todo, como es de ver, pero no hasta el punto de orillar los ideales de certeza, seguridad y notoriedad. Tal vez convenga terminar admitiendo como desideratum la vieja aspiración de Jeremy Bentham, para quien no debiéramos nunca dejar de plantearnos que cada cual fuera su propio abogado (each man his own lawyer). 